\title{
REFLEXÕES SOBRE O ENSINO DE BIOÉTICA
}

\author{
REFLECTIONS ABOUT BIOETHICS TEACHING
}

Márcia Maria de Medeiros* Luiz Alberto Ruiz da Silva** Luís Fernando Benitez Macorini*** Márcia Regina Martins Alvarenga**** Fábio Henrique Cardoso Leite*****

Resumo: A bioética é uma área de extrema importância para a formação dos profissionais da saúde. Ela se caracteriza por procurar construir conhecimentos críticos e reflexivos envolvendo muitos aspectos, entre eles a pesquisa com seres humanos e animais. Tendo em vista estes parâmetros, duas instituições de ensino superior da cidade de Dourados realizaram, em conjunto, um Seminário sobre o assunto, para promover a discussão das questões relativas a este campo entre os alunos dos cursos de biomedicina e enfermagem. Assim, foi realizado um projeto de extensão que se caracterizou pela realização de dez encontros, nos quais se discutiram os mais diversos temas referentes à área. No último encontro, os alunos foram convidados a opinar sobre a importância da temática para a sua formação. O presente artigo tem por objetivo discutir e descrever as reflexões feitas pelos docentes envolvidos no projeto em relação às respostas obtidas com os discentes. Concluiu-se que esse tipo de ação, além de promover a interação interinstitucional, é importante para os futuros profissionais para superar sua formação técnica, tornando-se aptos a trabalhar com problemas que surgem diariamente e que têm em si aspectos envolvendo questões éticas.

Palavras chave: Bioética; educação; formação de conceito.

Abstract: Bioethics is an area of extreme importance for the training of health professionals. It is characterized by seeking to build critical and reflective knowledge involving many aspects, including research with humans and animals. Based on these parameters, two institutions of higher education in the city of Dourados jointly held a seminar on the subject to promote the discussion of the issues related to this field among students of biomedicine and nursing courses. Also, an extension project was carried out, characterized by the accomplishment of ten meetings which discussed the most diverse subjects related to the area. In the last meeting the students were invited to give their opinion on the importance of the theme for their training. This article resulted from the reflections made by the teachers involved in the project in relation to the answers obtained with the students. This type of action, besides promoting interinstitutional interaction, was seen to be important for the future professionals to overcome their technical training, making them skilled to work with problems that arise daily and that have in themselves aspects involving ethical issues.

Keywords: Bioethics; education; concept formation. 


\section{Introdução}

A Bioética se caracteriza por ser uma área do conhecimento filosófico inerente ao campo da ética do conhecimento e que fomenta reflexão sobre os aspectos inerentes a tais prerrogativas, principalmente quando as mesmas envolvem a pesquisa com seres humanos e seus aspectos éticos. Nas mais diversas formações profissionais, esta área possui grande relevância, sendo fundamental para os futuros profissionais da área de saúde (SGRECCIA, 1994; COUTO FILHO et al., 2013; PAIVA; GUILHEM; SOUSA, 2014; MALUF; FAÇANHA, 2017).

A Bioética, segundo Pessini e Barchifontaine (1997), pode ser vista como um alicerce para as discussões envolvendo o ser humano enquanto objeto de pesquisa, e:

\begin{abstract}
[...] aparece no horizonte científico das novas descobertas como o estudo interdisciplinar dos problemas criados pelo progresso biomédico (seja em nível de relação individual, institucional ou mesmo de estrutura social), sua repercussão na sociedade e seu sistema de valores (PESSINI; BARCHIFONTAINE, 1997, p. 14).
\end{abstract}

Dessa forma, a ética/bioética "vista num contexto social, é uma tentativa de avaliar as ações pessoais e as ações dos outros de acordo com uma determinada metodologia ou certos valores básicos" (PESSINI; BARCHIFONTAINE, 1997, p. 14). Isso se deve ao fato de que a bioética age como uma espécie de "avaliação" de como nós, seres humanos, nos comportamos diante das diversas situações dentro de um determinado campo de atuação, sempre se preocupando com o que pode ocorrer a partir da decisão pela realização ou não de certas ações.

Historicamente, as preocupações com estas discussões nasceram com o Tribunal de Nuremberg, que, entre novembro de 1945 e outubro de 1946, julgou as "experiências" realizadas pelos médicos nazistas nos campos de concentração, levando a refletir sobre o que se estava fazendo com a humanidade em nome da ciência.

Para Durant (1995), as reflexões feitas nesta área devem ser trabalhadas em relação aos fatos e sobre os princípios e regras que norteiam o processo de construção das ações dos sujeitos envolvidos nas questões inerentes ao campo. Nesse sentido, vale ressaltar dois princípios fundamentais: "o respeito à vida; o respeito à autodeterminação da pessoa" (DURANT, 1995, p. 31).

Em 1966, o médico oncologista Henry K. Beecher publicou um artigo contendo 22 relatos de pesquisas realizadas com populações vulneráveis. Nele, o autor denuncia que essas não seguiram os principais preceitos instituídos até o momento, articulados a partir de Nuremberg (DINIZ; CORRÊA, 2001).
Beecher frisou que não bastava o pesquisador apenas recolher o Termo de Consentimento Livre e Esclarecido (TCLE) para iniciar sua pesquisa. Fazia-se necessário que ele explicasse ao participante da pesquisa quais seriam os objetivos, possíveis riscos e também os benefícios que aquele estudo traria para o participante. Dessa forma, e plenamente ciente de todo o processo, o sujeito da pesquisa tornar-se-ia agente de sua livre escolha no sentido da participação ou não no trabalho do pesquisador (BEECHER, 1966).

A bioética contemporaneamente está pautada em três princípios ou critérios que são fundamentais, ou como definem Pessini e Barchifontaine (1997), "a trindade bioética", quais sejam, a beneficência, a justiça e a autonomia. A Beneficência pode ser definida como fazer o bem e não causar nenhum dano ao sujeito da pesquisa. A Justiça está relacionada a como será feita a distribuição justa e equitativa dos possíveis benefícios da metodologia a que o sujeito está sendo submetido. Já a autonomia revela-se como sendo a capacidade de o sujeito de governar-se e saber avaliar sobre suas escolhas, sempre tomando a melhor decisão possível (PESSINI; BARCHIFONTAINE, 1997, p. 20).

Para Schuh e Albuquerque (2009), a bioética faz parte de um contexto que envolve uma série de elementos primordiais, como desvelo, solicitude, zelo, atenção, entre outros. As autoras partem da proposta de Leonardo Boff (1999) para se referir ao que é necessário na ação do cuidado. De acordo com as autoras:

\begin{abstract}
A bioética nasce de cientistas preocupados com o rumo das pesquisas, de médicos procurando orientar sua relação com os pacientes, de administradores hospitalares buscando critérios para o gerenciamento dos recursos, muitas vezes escassos, de moralistas tentando elaborar uma ética, de responsabilidade, de teólogos apresentando a experiência religiosa como construtora de sentido, e assim por diante (SCHUH; ALBUQUERQUE, 2009, p. 56).
\end{abstract}

Como se pode perceber, a bioética é uma área de conhecimento interdisciplinar (SCHRAMM, 2008; CLOTET, 1993; ANDRADE et al., 2016; REGO; PALACIOS, 2017). No Brasil, as linhas de atuação envolvendo as questões relacionadas à bioética privilegiam espaços de discussão que trazem à tona assuntos relativos à justiça social e a efetiva participação dos sujeitos da pesquisa enquanto agentes do processo que lhes é pertinente (GOMES, 1996). Esse contexto prevê que a população possa ter melhores condições em vários âmbitos e aspectos da vida humana.

Percebe-se, a partir de então, a importância de se discutir o conceito de pessoa, elemento central nesse locus, que envolve as questões inerentes à ética através da história da filosofia. A discussão desse conceito envolve mais nuances do que em um primeiro 
momento se pode considerar, pois a instituição de um "padrão" no que se refere à ética implica construir um caminho para alcançar um horizonte "situado lá adiante e que nunca se alcança" (PEGORARO, 2010, p.12).

Assim, qual o melhor caminho a seguir para se vislumbrar este horizonte, levando em conta o fato de que cada período histórico apresentará seus conceitos de justiça, solidariedade, suas próprias virtudes e suas iniciativas para promover o bem comum?

Contemporaneamente, este processo se alargou, pois, entre os valores do nosso tempo, agregaram-se os "fatos tecnocientíficos, biogenéticos e ecológicos" (PEGORARO, 2010, p. 13), os quais intuem a direta ação entre a trindade que institui a relação entre o Eu, o Outro e a Natureza, a qual tem visado o equilíbrio entre estas três esferas em uma sociedade capitalista de alto consumo (MARANDOLA JR.; HOGAN, 2006).

Paralelamente à relação entre o $\mathrm{Eu}, \mathrm{o}$ Outro e a Natureza, está uma bioética inter/multidisciplinar, em que a busca por informações se faz em um sentido mais amplo, em colaboração com as mais diversas ciências, visando sempre a melhor maneira para solucionar os problemas que envolvem o seu campo de ação (DURANT, 1995; ANDRADE et al., 2016).

Foi a partir deste prisma que o Seminário Interinstitucional de Bioética foi pensado, como um espaço onde debates, discussões e provocações sobre as questões que envolvem a bioética seriam colocados, com o intuito de perceber até que ponto a tecnociência tem, de fato, conseguido promover (ou está em busca de promover) este tão desejado equilíbrio.

Fischer et al. (2017) trilharam um caminho muito próximo ao proposto por este trabalho, ao se dedicarem a traçar uma proposta na qual a bioética dialogasse com as séries iniciais. Para tanto, buscaram - através de ferramentas simples, calcadas basicamente em recursos humanos - promover discussões que correlacionassem a academia, a sociedade e a escola, visando refletir sobre as questões inerentes à bioética, promovendo, assim, um amadurecimento intelectual e moral entre todos os envolvidos no projeto.

\section{Método}

O projeto de extensão denominado "Seminário Interinstitucional de Bioética" nasceu a partir de conversas realizadas entre professores da Universidade Estadual de Mato Grosso do Sul (UEMS) e do Centro Universitário da Grande Dourados (UNIGRAN), visando ampliar o conhecimento dos acadêmicos dos cursos de graduação da área de saúde de ambas as instituições, que estão localizadas em Dourados, Mato Grosso do Sul. O período em que o projeto ocorreu foi de março a junho de 2016, sempre aos sábados pela manhã, sendo conduzido por professores das duas instituições.

Também é importante frisar que, seguindo os preceitos interdisciplinares que regem a bioética, a formação dos professores participantes do Seminário na condição de ministrantes foi toda interdisciplinar: um biomédico, um educador físico, um filósofo, uma historiadora e uma enfermeira. É possível perceber que houve uma tentativa de entrelaçar as humanidades e a área da saúde, buscando-se a construção de um referencial mais complexo em relação ao tema.

Pensou-se a realização do Seminário a partir de dois momentos: reuniões entre os coordenadores dos cursos de graduação em Biomedicina da UNIGRAN e Enfermagem da UEMS, nas quais se estabeleceu o recorte necessário para a realização das atividades, sendo que, neste primeiro momento, o tema escolhido foi a questão da Bioética, dada a relevância do assunto na atualidade; e escolha dos professores coordenadores do projeto, os quais dimensionaram como deveriam ser realizadas as atividades no que tange ao processo de carga horária do Seminário, temas propostos a cada encontro e divisões dos encontros em palestras, mesas redondas e discussões envolvendo estudos de caso.

Concluídos estes dois passos iniciais, realizouse o desenvolvimento do projeto em si, que culminou em 10 encontros aos sábados pela manhã, contando com a presença média de 70 alunos por encontro. Os encontros seguiram uma ordem lógica, conforme preconizado pelos organizadores, disposta da seguinte maneira:

a.Primeiro encontro - Questões introdutórias sobre a Bioética, falando sobre o histórico que deu origem a esta área do conhecimento, relacionando-o ao Julgamento de Nuremberg. Ministrado pela professora Márcia Maria de Medeiros (UEMS);

b.Segundo encontro - Ética e Bioética e as suas relações, o qual abordou as questões conceituais inerentes a estas duas áreas da filosofia e a sua dimensão em relação ao ser humano. Ministrado pelo professor Fábio Henrique Cardoso Leite (UNIGRAN);

c.Terceiro encontro - Saúde e Direitos Humanos, temática que abordou e discutiu as questões sobre o conceito de saúde a partir do que foi idealizado pela Organização Mundial da Saúde (OMS), Organização Pan-Americana de Saúde (OPAS) e as suas relações no que tange ao processo da saúde pública no Brasil. Ministrado pela professora Márcia Regina Martins Alvarenga (UEMS);

d.Quarto encontro - Mesa redonda debatendo a importância do sistema CEP/CONEP e dos Comitês de Ética para a pesquisa científica 
envolvendo seres humanos. Participantes: professoras Márcia Maria de Medeiros; Márcia Regina Martins Alvarenga (UEMS) e professor Fábio Henrique Cardoso Leite (UNIGRAN);

e.Quinto encontro - Bioética e o uso de animais em pesquisa científica, que culminou com uma visita por parte dos alunos participantes do projeto às instalações do Biotério da UNIGRAN, para verificação in loco das questões abordadas no encontro. Ministrado pelo professor Luís Fernando Benitez Macorini (UNIGRAN);

f.Sexto encontro - Fases clínicas da experimentação científica, onde foram discutidos elementos de base farmacológica para a criação/administração de medicamentos em fase de testes em seres humanos, e também visita ao site "Registro Brasileiro de Ensaios Clínicos" para conhecimento de quais pesquisas estão ocorrendo no Brasil. Ministrado pelos professores Luís Fernando Benitez Macorini (UNIGRAN) e Luiz Alberto Ruiz da Silva (UEMS);

g.Sétimo encontro - Estudo da legislação envolvendo a pesquisa com seres humanos no Brasil, o qual abordou e analisou a Resolução $n^{\circ}$ 466/2012, que normatiza este processo. Ministrado pela professora Márcia Maria de Medeiros (UEMS);

h.Oitavo encontro - Bioética e suas relações com a Biotecnologia, no qual se discutiram fatos relacionados ao uso da biotecnologia para o desenvolvimento de produtos transgênicos; a área da engenharia genética, entre outras questões. Ministrado pela professora Márcia Maria de Medeiros (UEMS);

i.Encontros nono e décimo: Estudo de caso envolvendo questões inerentes à Bioética, com participação de todos os professores envolvidos no projeto e tutoria da professora Márcia Maria de Medeiros (UEMS).

Nestes dois últimos encontros, os alunos participantes do Projeto foram divididos em grupos e solicitou-se que cada grupo fizesse um relato sobre o caso que lhe foi atribuído através de sorteio, tendo por base as discussões teóricas realizadas durante todas as atividades.

Os grupos contaram com uma manhã de sábado para realizar as atividades de pesquisa e organizar o relato do seu estudo de caso, sendo que os temas escolhidos para estudo constam no quadro 1; e no último sábado realizaram-se as apresentações, bem como uma avaliação das atividades desenvolvidas.
Quadro 1 - Descrição dos casos clínicos apresentados e discutidos no I Seminário Interinstitucional sobre Bioética. Dourados-MS, 2016.

\begin{tabular}{|c|c|}
\hline Caso Clínico & \multicolumn{1}{c|}{ Descrição } \\
\hline Caso 1 & $\begin{array}{l}\text { 1963, Hospital de doenças crônicas de Nova Iorque - injeção de células } \\
\text { cancerosas vivas em idosos doentes. }\end{array}$ \\
\hline Caso 2 & $\begin{array}{l}1950 \text { a 1970, Hospital Estadual de Willowbrook (NY) - injeção de hepatite } \\
\text { viral em crianças com retardos mentais e dificuldades cognitivas. }\end{array}$ \\
\hline Caso 3 & $\begin{array}{l}\text { 1975, Karen Ann Quilan Case - pais da jovem entraram na justiça pelo } \\
\text { direito de desligar o respirador artificial que mantinha a fillha viva. }\end{array}$ \\
\hline Caso 4 & $\begin{array}{l}\text { 1982, Baby Doe I - nascido em abril de 1982, em Bloomington (Indiana), } \\
\text { menino com Síndrome de Down e fístula traqueosofágica. Os pais se } \\
\text { recusaram a realizar a correção cirúrgica do defeito. }\end{array}$ \\
\hline Caso 5 & $\begin{array}{l}\text { 1983, Baby Doe II - nascida em outubro de 1983, em Smithtown (NY), } \\
\text { menina com uma série de malformações. Os pais se recusaram à cirurgia } \\
\text { corretiva, pois a recém-nascida tinha como principais problemas } \\
\text { mielomeningocele (espinha bífida) e hidrocefalia. }\end{array}$ \\
\hline Caso 6 & $\begin{array}{l}\text { 2003, Cobaias Humanas do Amapá - grupo de quilombolas, de uma } \\
\text { comunidade ribeirinha no estado do Amapá, recebeu 12 reais por noite para } \\
\text { "caçar" mosquitos transmissores da Malária. }\end{array}$ \\
\hline Caso 7 & $\begin{array}{l}\text { 2013, Cães da raça Beagle serviam como cobaias do Instituto Royal. Cães } \\
\text { que eram usados em testes serviam para pesquisas sobre medicamentos que } \\
\text { seriam lançados. Ao inserir os testes nos cães, era possível verificar } \\
\text { possíveis reações adversas, como vômito, diarreia, perda de coordenação e } \\
\text { até convulsões. }\end{array}$ \\
\hline
\end{tabular}

Ao final das atividades do Seminário, os alunos participantes foram convidados a responder de forma discursiva, aberta e subjetiva a três questões propostas pelos organizadores do projeto:

a) Você considera que as atividades desenvolvidas no Seminário Interinstitucional de Bioética foram positivas para a sua formação profissional?

b) Você se interessaria em participar de um novo projeto relacionado à Bioética, na forma de outro Seminário como este?

c) Quais temas você gostaria de ver abordados ou aprofundados em uma próxima edição do Seminário?

Os organizadores do Seminário explicaram qual era a proposta desta atividade, ou seja, granjear elementos para organização de um novo projeto, tendo como referência os pontos a serem observados através das respostas coletadas pelo questionário.

Foi explicado a todos os participantes que nenhum deles teria a obrigatoriedade de responder ao questionário, e que em nada a não resposta os prejudicaria no que tange à certificação em relação ao mesmo. Todos os discentes envolvidos aceitaram participar da atividade e as respostas foram tabuladas conforme as tabelas em anexo neste artigo. Os questionários mantiveram o sigilo de cada discente envolvido, pois não era necessário que os mesmos se identificassem quando das suas respostas.

O projeto foi submetido a Plataforma do SigProj, protocolado e aprovado sob o número 166268.1146.2587.15022016, pois no momento em que foi implementado não havia, em nenhuma das instituições proponentes, a necessidade de que projetos 
de extensão fossem submetidos ao Comitê de Ética em Pesquisa com Seres Humanos.

\section{Resultados}

Dos alunos que responderam às questões, houve unanimidade em dizer que as atividades desenvolvidas durante os encontros foram importantes para a formação profissional dos sujeitos, tornando-os mais críticos, reflexivos e conscientes da sua responsabilidade futura em relação ao ser humano, enquanto profissionais da área de saúde, e também àqueles que optarem por pesquisa envolvendo animais.

Também houve unanimidade em afirmar que participariam de um novo Seminário, com o intuito de aprofundar seus conhecimentos e ampliar o seu escopo futuro de trabalho, preconizando inclusive pesquisas na área da Bioética a serem desenvolvidas em sua carreira futura.

Quanto aos temas a serem abordados ou aprofundados em uma nova edição, constam entre os principais: questões referentes à morte (eutanásia e distanásia), com $43,29 \%$ dos pedidos; e aborto, com $28,36 \%$ das sugestões. $\mathrm{Na}$ categoria outros, $28,35 \%$ sugestões de temas foram divididas em várias possibilidades, como, por exemplo, clonagem humana e religião e ciência.

Os temas mais pedidos podem ser considerados de alta complexidade em termos de discussão, mostrando que os participantes envolvidos querem ampliar seus conhecimentos em Bioética promovendo debates de relevância para a sociedade contemporânea.

Isso significa que os sujeitos envolvidos entenderam o quão complexa é a realidade deste universo e o quão é falha, em termos sociais, a maioria dos códigos de ética que se pautam no trato com os seres humanos ou com os animais (SCHUH; ALBUQUERQUE, 2009).

A ação do Seminário permitiu que eles se perguntassem como se dá a sua formação ética enquanto pessoa e enquanto profissional, ampliando os princípios propostos pela própria Resolução 466/2012, a qual, segundo Rippel, Medeiros e Maluff apresenta um conteúdo cuja tônica discursiva é "vinculada à prática diária dos profissionais de saúde e restrita às condutas principialistas" (RIPPEL, MEDEIROS; MALUFF, 2016, p. 611), garantindo, assim, um pressuposto crítico e reflexivo, necessário a formação de futuros profissionais da saúde.

Neste contexto, foi importante observar que as práticas instituídas pelas ações do Seminário promoveram princípios de formação que garantiram aos sujeitos participantes o entendimento de algumas questões importantes referentes ao atendimento das peculiaridades que a sua prática profissional futura exigirá, principalmente no que tange ao respeito as diferentes formas de ver o mundo e de ser no mundo.

Esse processo demonstra que houve uma aproximação entre a realidade prática que os espera e o universo acadêmico no qual agora estão contidos, pois as temáticas que prevaleceram enquanto futuros assuntos a serem abordados em novo Seminário auferem questões correlacionadas a práxis cotidiana dos profissionais da saúde.

Percebeu-se, também, a partir dos resultados, uma aproximação em relação às questões que envolvem a humanização no processo de formação dos profissionais desta área, a qual é preconizada pelo próprio Ministério da Saúde em suas prerrogativas.

\section{Considerações finais}

O ensino superior deveria se caracterizar por ter como princípio básico a formação de profissionais capazes de atender as necessidades das regiões onde exercerão suas profissões e que, preferencialmente, estes profissionais sejam capazes de respeitar a diversidade e a pluralidade de formas de ver o mundo e de ser no mundo com as quais conviverão.

Pensando neste sentido, as ações extensionistas representam, sem dúvida, a ponta de lança deste processo formativo, meio mais eficaz para reatar os laços entre a academia e o meio que a cerca, permitindo a convivência de pessoas em processo de formação com as necessidades que o espaço onde atuarão possui.

No caso dos profissionais da saúde, uma das mais prementes necessidades observadas atualmente apesar das tentativas por parte do Ministério da Educação de traçar linhas formativas mais humanizadas - está justamente em definir e articular até que ponto estes sujeitos têm efetivo poder sobre a vida dos sujeitos que procuram pelos seus serviços. Ou até que ponto estes sujeitos podem ser utilizados nas pesquisas com seres humanos, sem que isso seja fator que lhes fira a integridade física, psicológica ou ambas.

$\mathrm{Na}$ ação desenvolvida neste Seminário, houve por esforço entre as instituições coligadas para sua realização pensar a universidade como um palco que fomente, no futuro profissional, o desejo da investigação científica pautada em preceitos e critérios éticos e de respeito ao ser humano e aos animais.

Durante as atividades desenvolvidas no Projeto, houve um cuidado por parte dos professores participantes do processo em tratar os temas 
trabalhados de forma ativa, promovendo discussões, o que incitou a participação dos alunos, que foi bastante considerável, dado o interesse demonstrado por eles durante a abordagem dos temas, acarretando em posicionamentos críticos, oriundos da sua fala.

Esta ação de aprendizado teve como prerrogativa permitir entre os participantes do projeto, tanto os professores ministrantes ou os alunos, uma construção de conhecimento pautada na dialética. Também foi possível perceber o quanto o contexto social dos indivíduos envolvidos no projeto funcionou como arcabouço para a constituição de conhecimentos, a partir das teorizações realizadas.

Essa conduta permite afirmar que houve uma incorporação, por parte dos discentes participantes do projeto, de elementos fulcrais para o seu desenvolvimento enquanto cidadãos, não apenas na dimensão do sujeito enquanto indivíduo, mas também na dimensão do sujeito enquanto membro de uma coletividade.

Há que se salientar a importância desta questão, uma vez que, efetivamente, a maioria dos alunos participantes das atividades constitui-se de acadêmicos que se encontram nos primeiros períodos de seus respectivos cursos de graduação. Assim sendo, o seminário ajudou a ampliar de forma decisiva a sua formação, permitindo uma efetivação na lógica do pensamento que preconiza o equilíbrio entre $\mathrm{Eu}, \mathrm{o}$ Outro e a Natureza, e uma abordagem inter/multidisciplinar, tão complexa de se alcançar na sociedade ocidental contemporânea.

As temáticas propostas para uma nova edição permeiam campos do conhecimento como a Tanatologia, os quais ainda apresentam inúmeros caminhos a serem desvendados, mas que revelam que o Seminário atingiu a sua finalidade, qual seja, construir nos participantes uma visão mais crítica da sua posição não só enquanto futuros profissionais, mas também enquanto cidadãos participes de uma coletividade na qual a sua ação ou a sua omissão pode interferir no jogo das relações de poder.

Por fim, é importante frisar o quanto a formação dos profissionais na área de saúde carece de mais atividades como esta, as quais abrem espaços para que temas que ficam ocultos no seu currículo sejam abordados. Essas ações são imperativas para que os futuros profissionais não se desenvolvam apenas dentro de uma formação tecnicista, mas que também estejam aptos para trabalhar problemas que lhes podem surgir no cotidiano e que tenham em si aspectos morais. Também vale ressaltar que este não é um tema que se fecha em si, pois a capacidade de ação ética e de julgamento é um processo que o sujeito adquire durante toda a sua vida.

\section{Referências}

ANDRADE, A. F. L.; et al. Processo Ensino-Aprendizagem em Bioética: um Debate Interdisciplinar. Revista Brasileira de Educação Médica, v. 40, n. 1, p. 102-108, 2016.

BEECHER, H. K. Ethics and clinical research. The New England Journal of Medicine, v. 274, n. 24, p. 1354-1360, 1966.

BOFF, L. Saber cuidar: ética do humano. Compaixão pela terra. Petrópolis: Vozes, 1999.

CLOTET, J. Por que bioética? Revista Bioética, v. 1, n. 1, p. 8-14, 1993.

COUTO FILHO, J. C. F. et al. Ensino da Bioética nos cursos de Enfermagem das universidades federais brasileiras. Revista Bioética, v. 21, n. 1, p. 179-185, 2013.

DINIZ, D.; CORRÊA, M. Declaração de Helsinki: relativismo e vulnerabilidade. Caderno de Saúde Pública, v. 17, n. 3, p. 679-688, 2001.

DURANT, G. A bioética: natureza, princípios, objetivos. São Paulo: Paulus, 1995.

FISCHER, M. L. et al. Caminho do Diálogo: uma experiência bioética no ensino fundamental. Revista Bioética, v. 25, n. 1, p. 89-100, 2017.

GOMES, J. C. M. O atual ensino da ética para os profissionais de saúde e seus reflexos no cotidiano do povo brasileiro. Revista Bioética, v. 4, n. 1, p. 35-45, 1996.

MARANDOLA JR., E.; HOGAN, D. J. As dimensões da vulnerabilidade. São Paulo em Perspectiva, v. 20, n. 1, p. 33-43, 2006.

PEGORARO, O. A. Ética e Bioética: da subsistência à existência. Petrópolis: Vozes, 2010.

MALUF, F.; FACANHA, T. R. S. A presença do ensino da bioética na Enfermagem. Revista Pró-UniverSUS, v. 8, n. 1, p. 17-25, 2017.

PAIVA, L. M.; GUILHEM, D.; SOUSA, A. L. L. O Ensino da bioética na graduação do profissional de saúde. Medicina (Ribeirão Preto. Online), v. 47, n. 4, p. 357-369, 2014.

PESSINI, L.; BARCHIFONTAINE, C. P. Problemas atuais de bioética. 2.ed. São Paulo: Ediçõos Loyola, 1997.

REGO, S.; PALACIOS, M. Contribuições para planejamento e avaliação do ensino da bioética. Revista Bioética, v. 25, n. 2, p. 234-243, 2017.

RIPPEL, J. A.; MEDEIROS, C. A.; MALUF, F. Declaração Universal sobre Bioética e Direitos Humanos e Resolução 466/2012: análise comparativa. Revista Bioética, v. 24, n. 3, p. 603-612, 2016.

SCHRAMM, F. R. Bioética da proteção: ferramenta válida para enfrentar problemas morais na era da globalização. Revista Bioética, v. 16, n. 1, p. 11-23, 2008.

SCHUH, C. M.; ALBUQUERQUE, I. M. A ética na formação dos profissionais da saúde: algumas reflexões. Revista Bioética, v. 17, n. 1, p. 55-60, 2009.

SGRECCIA, E. Manual de Bioética. São Paulo: Martins Fontes, 1994. 